\title{
Galvanic Corrosion of Copper / Nickel-Chrome Alloy in an Agitated Sulfuric Acid Solution
}

\author{
Samar S. Hussein \\ Production Eng. and Metallurgy Dep. \\ University of Technology \\ Baghdad, IRAQ \\ samar_saadi@yahoo.com \\ Received: 20-Sep.-2017 \\ http://doi.org/10.29194/NJES21010133
}

\author{
Basim O. Hasan \\ Chemical Eng. Dep. \\ Al-Nahrain University \\ Baghdad, IRAQ \\ Basimohasan13@gmail.com \\ Naseer A. Al-Haboubi \\ Chemical Eng. Dep. \\ Al-Nahrain University \\ Baghdad, IRAQ \\ naseer@habobi.com
}

\begin{abstract}
Galvanic corrosion of Nickel-Chrome alloy (Ni$\mathrm{Cr}$ alloy) and Copper (Cu) coupled in 5\% sulfuric acid solution was investigated. The effects of agitation velocity, temperature, and time on the galvanic corrosion current and the weight loss of both metals in both free corrosion and galvanic corrosion were investigated. The trends of open circuit potential (OCP) of each metal and galvanic potential $(\mathrm{Eg})$ of the couple were also determined. The results showed that $\mathrm{Cu}$ was cathodic relative to $\mathrm{Ni}-\mathrm{Cr}$ alloy in galvanic couple and the corrosion potential of the couple (Ni- $\mathrm{Cr}$ alloy /Cu) was between the values of the two single components because the OCP of copper shifted to positive with the increase in velocity. Under stagnant conditions initially the galvanic current was more negative then shifted to the positive with time. The corrosion of Ni-Cr alloy decreased with time because the passivation layer was formed on the surface. Under flow conditions, the galvanic current sharply shifted to the negative direction (increase galvanic current from Ni-Cr alloy (anode) to $\mathrm{Cu}$ (cathode) during the first few minutes.
\end{abstract}

Keywords: galvanic current; corrosion rate; copper; Nickel -Chrome; rotational speed

\section{Introduction}

Galvanic corrosion occurs when two different metals become in electrical contact. The more negative pole is the anode from which the current is flowing to the more positive pole which is the cathode [1].

Corrosive acid media such as hydrochloric acid ( $\mathrm{HCl})$ and sulfuric acid $\left(\mathrm{H}_{2} \mathrm{SO}_{4}\right)$ are widely encountered in practical applications such as acid pickling, removal of scales using acids, cleaning of oil wells by acidizing method and others.

Nickel and its alloys have wide applications in practice such as the use of pure nickel as a protective covering for other metals and alloys and the use of nickel and alloying element with other metals. In general, nickel has a good resistance to corrosion, and its alloys exhibit a considerable corrosion resistance to various environments. However, in acidic media the nickel could be attacked in a considerable rate [2]. The formation of passive film on the surface of nickel improves its corrosion resistance. However, the removal of this film by the effect of flow velocity or mechanical way may lead to enhance the corrosion. CopperNickel alloy applications are various such as coating of steel by copper-Nickel to increase its corrosion resistance and the use of Copper-Nickel in the construction of boat hulls [3].

In the medium of low $\mathrm{H}_{2} \mathrm{SO}_{4}$ concentrations, it was found that the passive film that forms on nickel surface is $\mathrm{NiOOH}$ or $\mathrm{NiO}$ and $\mathrm{Ni}_{2} \mathrm{O}_{3}$. In high $\mathrm{H}_{2} \mathrm{SO}_{4}$ concentrations of sulfuric acid, it was found that the passive film was composed of $\beta$ $\mathrm{NiSO}_{4} \cdot 6 \mathrm{H}_{2} \mathrm{O}$ [2].

Copper and its alloys are extensively used in industrial applications for condensers, evaporators, heat exchangers, etc. This equipment may also being exposed to corrosive solutions that are of different acidity. Copper is corrosion resistant to non-oxidizing acid environments because it does not displace hydrogen from acid solution. However, it can be attacked by dissolved air in the acidic environments. The corrosion process depends on nature of the metal surface, nature of the the solution, temperature of environment and on the electrochemical potential at the metal-solution interface [4].

Under flow conditions, the corrosion behavior of most metals in different environments may be complicated due to the complicated influence of the combined effect hydrodynamics and corrosion reactions on the metal surface. Over the years, the literature studied for the effect of flow velocity on the galvanic corrosion reported different trends of the corrosion versus flow velocity.

From practical point of view, it is important to understand the corrosion behavior of the practically important metals and alloys such as copper and nickel in the corrosive environment under different operating conditions. Therefore, the current work is devoted to investigate the free corrosion and galvanic corrosion behavior of Nickel- Chrome alloy and copper in sulfuric acid under different flow conditions.

\section{Experimental work}

The free corrosion rate for specimens $\mathrm{Ni}$ - $\mathrm{Cr}$ alloy and $\mathrm{Cu}$ was determined by weight loss 
method under agitation velocity of 0,400 , and 600 rpm and temperatures of $30,40,50$ and $60^{\circ} \mathrm{C}$, in a solution of $5 \% \mathrm{H}_{2} \mathrm{SO}_{4}$. Galvanic corrosion rate of $\mathrm{Ni}-\mathrm{Cr}$ alloy /with $\mathrm{Cu}$ couple was evaluated under isothermal conditions $\left(\mathrm{T}=40{ }^{\circ} \mathrm{C}\right)$ and agitation velocity 0,400 , and $600 \mathrm{rpm}$. Figure (1) shows the experimental apparatus that was used in galvanic corrosion experiments. The corrosion rate for two dissimilar metals was calculated from the measured weight loss before and after coupling. The electrode specimens were mechanically press-cut into coupons of $20 \mathrm{~mm} \times 40 \mathrm{~mm}$ dimensions with a total specimen surface area of $800 \mathrm{~mm}^{2}$. The specimens were connected to a plastic board through a very small holes made in the center using fine screw. The effect of screw was ignored. The chemical composition of specimen is shown in Table 1 and 2.

The analyses of chemical compositions were carried out in the Ministry of Science and Technology/ Department of Material Researches.

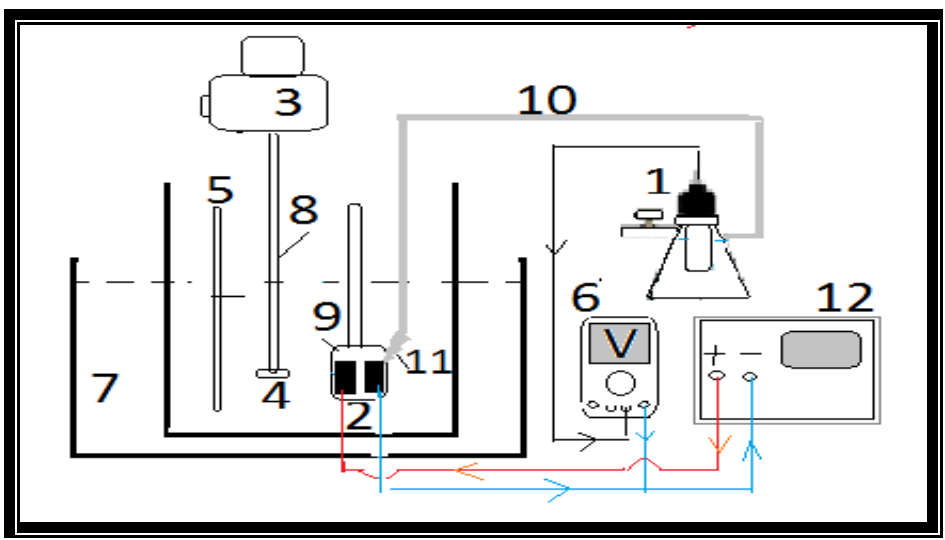

Figure 1: Galvanic experiment set-up: 1- Reference Saturated Calomel Electrode (SCE), 2- specimens (Cu is connected to-ve terminal of ZRA and Ni-Cr to the positive), 3-Motor, 4- Stirrer, 5- Thermometer, 6Voltmeter, 7- Water bath, 8- Glass shaft, 9- Holder of specimens, 10- Rubber, 11- Luggen capillary tube, 12Zero Resistance Ammeter (ZRA).

Table 1: Chemical composition of nickel- chrome alloy specimen

\begin{tabular}{|c|c|c|c|c|c|c|}
\hline Nickel_chrome alloy & $\begin{array}{c}0.36 \% \\
\mathrm{Ti}\end{array}$ & $\begin{array}{c}12.52 \% \\
\mathrm{Cr}\end{array}$ & $\begin{array}{c}0.07 \% \\
\mathrm{Mn}\end{array}$ & $\begin{array}{c}19.20 \% \\
\mathrm{Ni}\end{array}$ & $\begin{array}{c}0.07 \% \\
\mathrm{Mo}\end{array}$ & $\begin{array}{c}\text { Balance } \\
\text { Fe }\end{array}$ \\
\hline
\end{tabular}

Table 2: Chemical composition of copper specimen

\begin{tabular}{|c|c|c|c|c|c|c|c|c|}
\hline \multirow{2}{*}{ Copper } & $0.011 \%$ & $0.454 \%$ & $0.685 \%$ & $0.067 \%$ & $0.012 \%$ & $0.093 \%$ & $29 \%$ & Balance \\
$\mathrm{p}$ & $\mathrm{C}$ & $\mathrm{Mn}$ & $\mathrm{Cr}$ & $\mathrm{Mo}$ & $\mathrm{Ni}$ & $\mathrm{Fe}$ & $\mathrm{Cu}$ \\
\hline
\end{tabular}

Before each test run, the metal specimen was abraded with glass emery paper of grade numbers: 120, 180, 220, 400 and 2000 respectively, washed by tap water followed by distilled water, dried with a clean tissue followed by ethanol for 30 seconds, dried with clean tissue, and then dried by using electrical oven at a temperature of $110{ }^{\circ} \mathrm{C}$ for 10 minutes [5,6,7].

The specimen was stored in the desiccator over a high activity silica gel until use. Before immersion test, the specimen was weighed to the $4^{\text {th }}$ decimal of gram. One face of the rectangular coupon was exposed to corrosion environment for $1 \mathrm{~h}$ immersion in the acid solution, while the other face was completely insulated by insulating tape. The corrosion rate of each specimen was determined for two cases: free corrosion and galvanic corrosion. At the end of weight loss experiment, the specimen was washed by tap water with brushing to remove the corrosion products that may still sticking surface, washed with distilled water, dried with clean tissue, rinsed in ethanol and dried by using electrical oven to a temperature about $110^{\circ} \mathrm{C}$ for 10 minute. Then the specimen was kept in the desiccator in presence of high activity silica gel until weighing. The change in the open circuit potential of specimen as function of time was measured for experimental runs.

In galvanic corrosion experiments, before each experiment, the specimens were weighed by accurate balance. After the solution had reached the required isothermal temperature and velocity, the two dissimilar metals were connected together to measure galvanic current variation with time by using Zero Resistance Ammeter (ZRA). The nickel chrome alloy specimen was connected to the (+ve) and the copper to the (-ve). The distance between the specimens in the test solution was maintained at $10 \mathrm{~mm}$ in all experiments. The 
coupons were mounted by connecting them on hold board using a small screw.

During each experimental run, the variation of galvanic potential with time was measurement by using Saturated Calomel Electrode SCE bridged by a Luggin capillary at a distance of $1-2 \mathrm{~mm}$ from the working electrode [8] connected to personal computer for data recording. The specimens were immersed in the acid solution for $1 \mathrm{~h}$. During this time period, the galvanic current and galvanic potential were measured with time. After each run, the specimens were weighted by high accuracy balance. Each run was repeated at least twice.

\section{Results and discussion \\ 3.1 Free corrosion}

Figures 2 and 3 illustrate the variation of corrosion rate of Nikel-Chrome alloy (Ni-Cr alloy) and Copper (Cu) expressed in gmd with temperature and agitation velocity for a $1 \mathrm{~h}$ of immersion time in $0.52 \mathrm{M} \mathrm{H}_{2} \mathrm{SO}_{4}$ solution. Figure (2) reveals that the corrosion rate increases with temperature. This effect may be attributed to the increased diffusion rate of hydrogen and oxygen with the increase in temperature. The temperature favors the kinetics of the corrosion reaction $[9,10]$, and specially the anodic dissolution of the metal, because the anodic current densities increase with the increase in temperature.

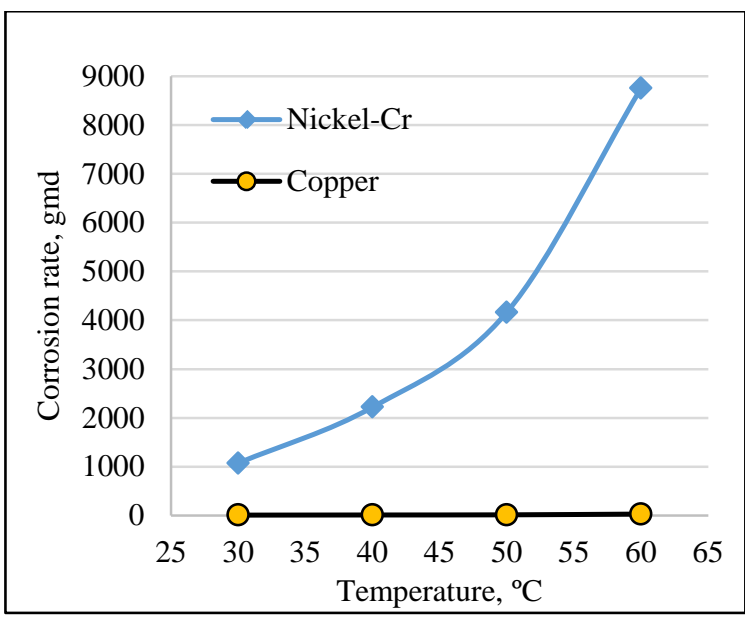

Figure 2: Variation of corrosion rate with temperature at stationary condition.

Figure (3) shows the corrosion rate versus agitation velocity for $\mathrm{Ni}$ _ $\mathrm{Cr}$ alloy at $\mathrm{T}=40^{\circ} \mathrm{C}$. It is clear that the corrosion rate increases linearly with increasing velocity. Figures 2 and 3 reveal that the corrosion rate of $\mathrm{Ni}-\mathrm{Cr}$ alloy exhibits high corrosion rate compared to $\mathrm{Cu}$. In addition, their corrosion rate increases appreciably with temperature. Copper exhibited a clear corrosion resistance under most investigated conditions even at high temperature and high rotational speed. This is due to the increased anodic polarization and a possibility of passivation. The clear increase of the corrosion rate with temperature is ascribed to two main reasons [5,8]: the first one is the increased anodic dissolution reaction of metal due to the decrease in activation energy of anodic reaction. The second one is the increased oxygen diffusivity that leads to increase the arrival of oxygen to the metal surface and hence enhance the corrosion.

Figure 4 and 5 show the corrosion potential (open circuit potential) versus time for $\mathrm{Ni}-\mathrm{Cr}$ alloy and $\mathrm{Cu}$ respectively in $0.52 \mathrm{M} \mathrm{H_{2 } \mathrm { SO } _ { 4 }}$ solution at four different temperatures of 30, 40, 50 , and $60^{\circ} \mathrm{C}$, for stationary condition. Figure (4), for Ni-Cr alloy, indicates that in the beginning of the run a high $\mathrm{E}_{\text {corr }}$ is noticed, which decays quickly. This high initial potential is due to the oxide film formed. After the immersion this films undergoes reductive dissolution and the corrosion potential decreases. Following the reductive in potential, the potential built up in the positive direction, suggestive of film formation and repair. At all temperatures the potential shifts toward more negative values directly after the immersion and then slightly increases to more positive. This rise in temperature may decreases the equilibrium potential of $\mathrm{Fe}$ and $\mathrm{H}_{2}$ but increase the equilibrium potential of $\mathrm{O}_{2}$ [11]. The diffusion rate of oxygen species is increased by increasing the molecular diffusion coefficient and the oxygen solubility is decreased. This result agrees with Hasan et al., 2011 [12] for carbon steel in $0.1 \mathrm{~N} \mathrm{NaCl}$ solution.

From Figure 5 for $\mathrm{Cu}$, it can be seen that the OCP from -580 to $-490 \mathrm{mV}$, and it increase about $80 \mathrm{mV}$ with increase of temperature to $60{ }^{\circ} \mathrm{C}$. Moreover, it is clear that not change in OCP when temperature changes from 30 to $50{ }^{\circ} \mathrm{C}$ while more important change when up to $60^{\circ} \mathrm{C}$. At high temperature $\left(\mathrm{T}=60{ }^{\circ} \mathrm{C}\right)$, the corrosion potential shifts to more positive indicating the formation of oxide film $\left(\mathrm{Cu}_{2} \mathrm{O}\right)$ on the metal surface. At $\mathrm{T}=30$ to $50{ }^{\circ} \mathrm{C}$, it exhibits potential shift to more negative with time reaching an asymptotic value of $-0.57 \mathrm{~V}$ after about $30 \mathrm{~min}$. At $\mathrm{T}=60{ }^{\circ} \mathrm{C}$ the potential also shifts to negative and reach asymptotic value of $-0.49 \mathrm{~V}$ after about $20 \mathrm{~min}$.

Figures 6 and 7 shows the effect of agitation speed on the corrosion potential vs. time of $\mathrm{Ni}-\mathrm{Cr}$ alloy and $\mathrm{Cu}$ respectively, in $0.52 \mathrm{M} \mathrm{H}_{2} \mathrm{SO}_{4}$ solution at $\mathrm{T}=40{ }^{\circ} \mathrm{C}$. Figure 6 shows the free corrosion potential versus time for Ni_Cr alloy for various velocities at $\mathrm{T}=40{ }^{\circ} \mathrm{C}$. It is clear that with increasing velocity the potential shifts to more positive values due to the increased $\mathrm{O}_{2}$ transport to the surface. This agrees with previous studies $[13,5,14,15,12]$. The anodic kinetics (dissolution of metal) is not mass transfer dependent as it is under activation control while 
the oxygen reduction reaction is dictated by the limiting values of mass transfer control. This may be explaining the noble trend of the corrosion potential as the flow rate (rpm) is increased as shown in Figure (6). This agrees with previous findings [16,17,18]. Ross et. al., 1966 [16] indicated that the increase in $\mathrm{E}_{\text {corr }}$ with velocity because of the increase in transport of oxygen to the metal surface and velocity has no effect on corrosion potential $\left(\mathrm{E}_{\text {corr }}\right)$ when the system is free from oxygen. Figure 7 for $\mathrm{Cu}$, Following the initial dissolution of potential, the potential leveled down slowly to constant values. It is clear that the OCP shifts to more positive with increase velocities. Magaino, 1997[19] reported that the amount of copper dissolved in acid media decreased with electrode-rotation but remained almost constant at the rotation speeds above 500 rpm.

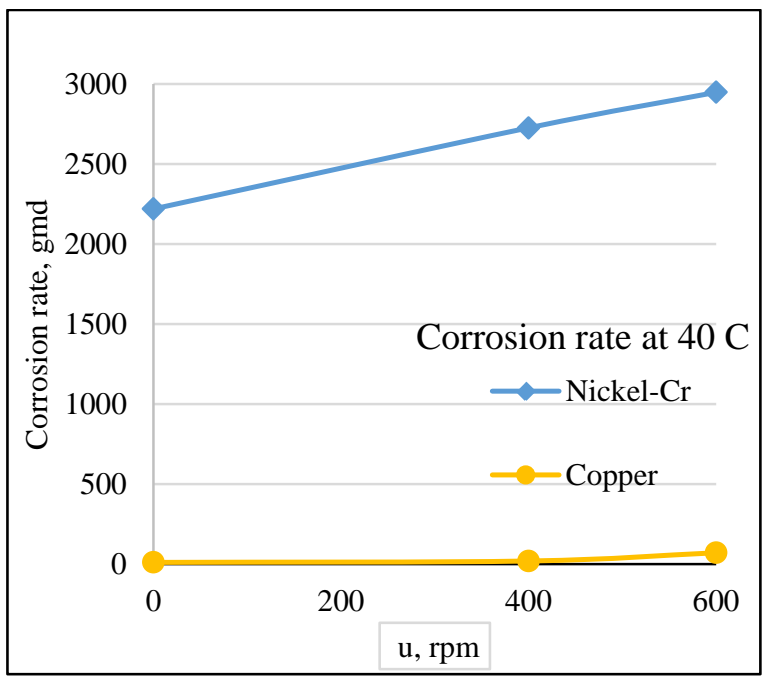

Figure 3: Corrosion rate vs. velocity of $\mathrm{Ni}-\mathrm{Cr}$ alloy and $\mathrm{Cu}$ at $\mathrm{T}=40^{\circ} \mathrm{C}$.

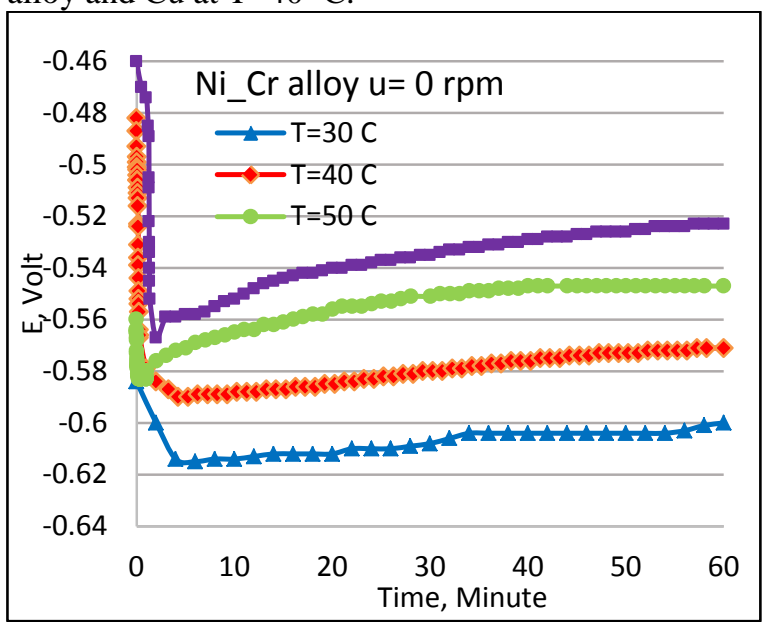

Figure 4: Corrosion potential vs. time of NickelChrome alloy specimen at stationary condition at different temperature.

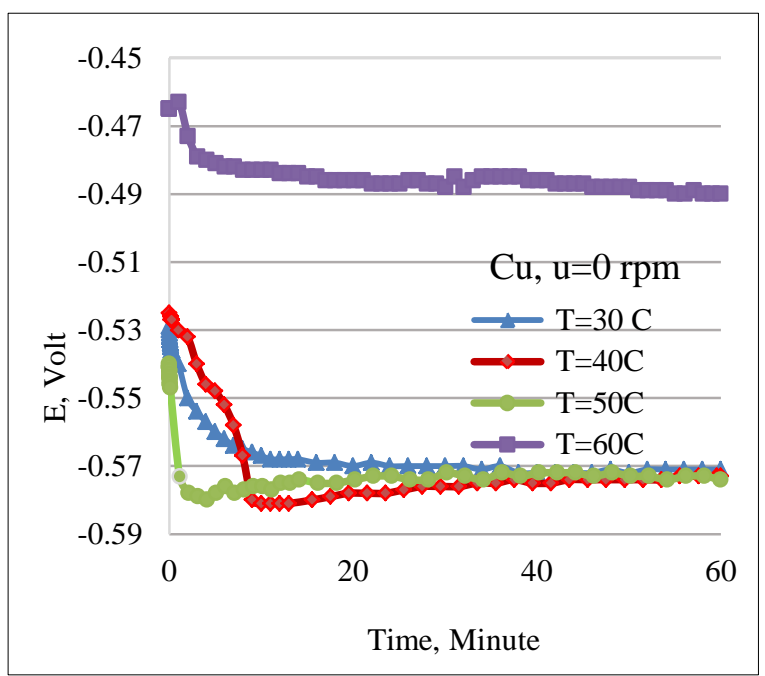

Figure 5: Corrosion potential vs. time of copper specimen at stationary condition at different temperature.

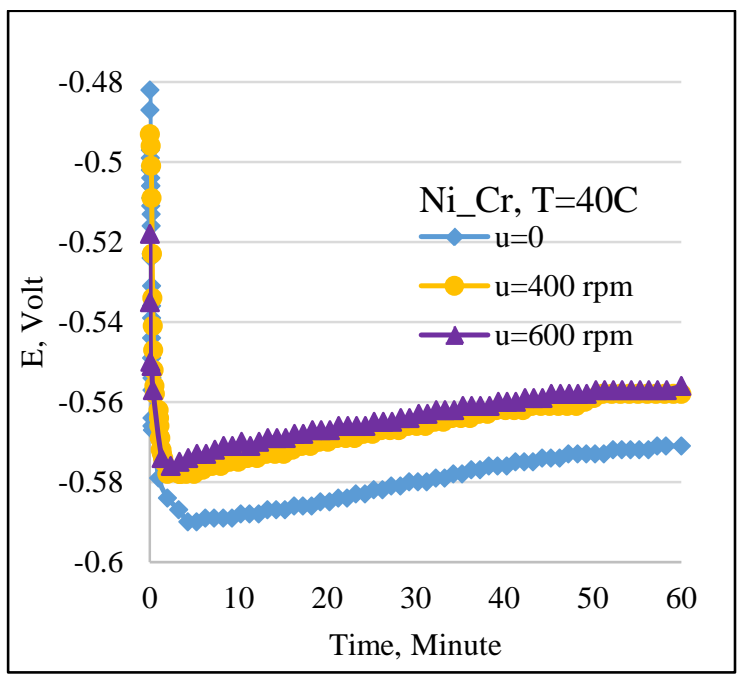

Figure 6: Corrosion potential vs. time of $\mathrm{Ni}-\mathrm{Cr}$ alloy at different velocity and $40{ }^{\circ} \mathrm{C}$.

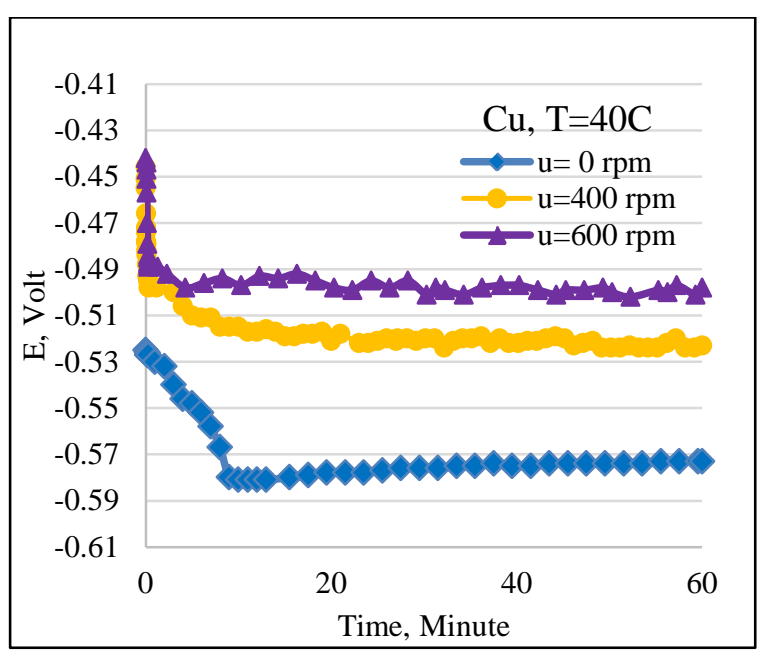

Figure 7: Corrosion potential vs. time of $\mathrm{Cu}$ at different velocity and $40^{\circ} \mathrm{C}$. 


\subsection{Galvanic corrosion}

Figure 8 shows the comparison of three cases: free corrosion potential of $\mathrm{Ni}_{-} \mathrm{Cr}$ alloy, $\mathrm{Cu}$, and galvanic potential of $\mathrm{Ni}-\mathrm{Cr} / \mathrm{Cu}$. In general there is a sharp decrease in the potentials and then a slight increase with time. It can be seen that the galvanic potential of the $\mathrm{Ni}-\mathrm{Cr}$ alloy $/ \mathrm{Cu}$ couple is more noble than OCP of $\mathrm{Cu}$ and $\mathrm{Ni}-\mathrm{Cr}$ alloy respectively. This attributed to the instability of the film freely formed on the copper under conditions of galvanic coupling. This result is in agreement with previous observations [20] for steel and 70/30 Cu-Ni alloy couple in sea water. This figure reveals that the nickel-chrome alloy is the anode because its corrosion potential is more negative than the copper.

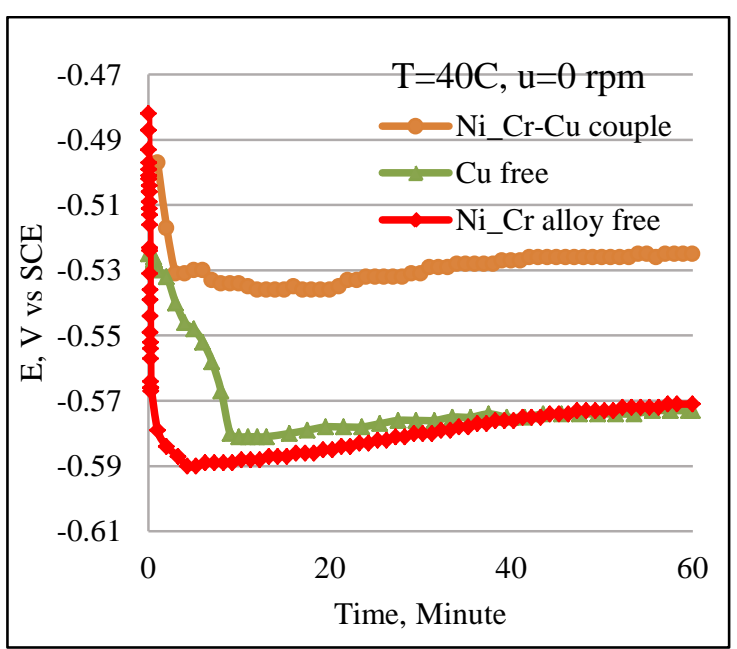

Figure 8: OCP and galvanic potential versus time of $\mathrm{Ni}_{-} \mathrm{Cr}$ alloy and $\mathrm{Cu}$ at const. temperature $\left(\mathrm{T}=40^{\circ} \mathrm{C}\right)$ and stationary $(\mathrm{u}=0 \mathrm{rpm})$.

Figure 9 and 10 shows the potential variation with time for $\mathrm{Ni}_{-} \mathrm{Cr}$ alloy, $\mathrm{Cu}$, and $\mathrm{Ni} \mathrm{Cr}_{-} \mathrm{Clloy-}$ $\mathrm{Cu}$ couple for agitation velocities of 400 and 600 $\mathrm{rpm}$ at $\mathrm{T}=40^{\circ} \mathrm{C}$ respectively. The figures reveal the corrosion potential of the couple $(\mathrm{Ni}$ _ $\mathrm{Cr}$ alloy - $\mathrm{Cu}$ ) lies between the values of the two single components due to OCP of copper shift to positive with increase velocity. This result agreement with A1 Hossani et al., 1997 [20] for steel incorporating with Al-bronze and 90/10 Cu$\mathrm{Ni}$ alloy in sea water and Montanes et al., 2009 [21] for copper and AISI 304 steel pair in $\mathrm{LiBr}$ solution. Since the open circuit potential of copper is higher than the open circuit potential of $\mathrm{Ni}_{\text {_ }} \mathrm{Cr}$ alloy, the current is flow from nickel_ chrome alloy to copper. Therefore, the nickel_ chrome alloy is the anode and copper is the cathode.

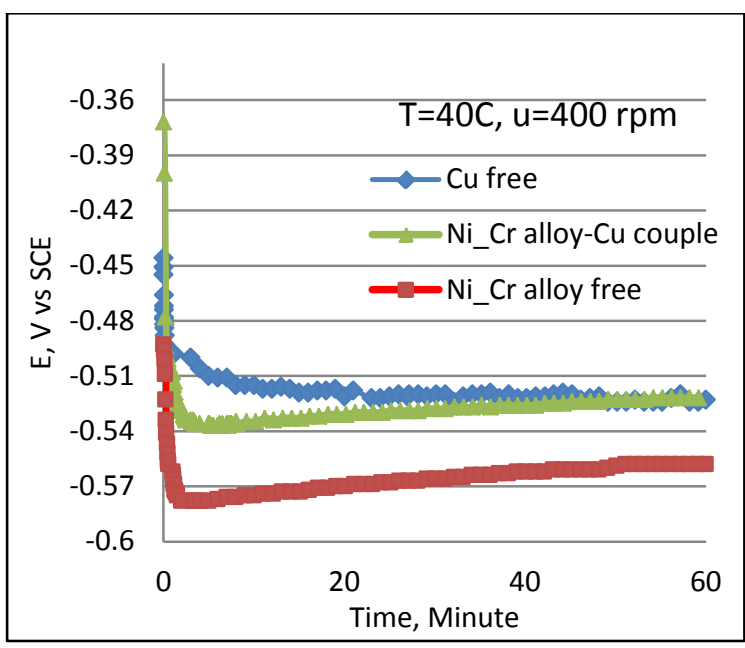

Figure 9: Potentials of $\mathrm{Ni}-\mathrm{Cr}$ alloy, $\mathrm{Cu}, \mathrm{Ni}-\mathrm{Cr}$ alloy /Cu couple for $\mathrm{u}=400 \mathrm{rpm}$.

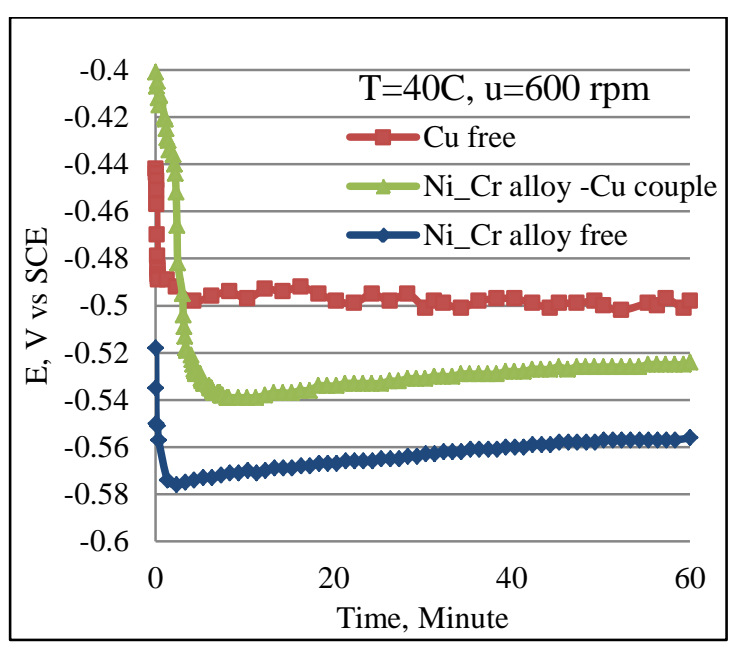

Figure 10: Potentials of $\mathrm{Ni}_{-} \mathrm{Cr}$ alloy, $\mathrm{Cu}, \mathrm{Ni}_{-} \mathrm{Cr}$ alloy $-\mathrm{Cu}$ couple for $\mathrm{u}=600 \mathrm{rpm}$.

Figure (11) shows the effect of agitation velocities on galvanic potential of $\mathrm{Ni}_{-} \mathrm{Cr}$ alloy $\mathrm{Cu}$ couple at $\mathrm{T}=40^{\circ} \mathrm{C}$. Following the initial sharp decrease in galvanic potential of couple $(\mathrm{Ni}-\mathrm{Cr}$ alloy - $\mathrm{Cu}$ ) in the first minutes, a slight increase in potential occurs. This trend agrees with Hasan, 2014 [22]. The effect of flowing condition is approximately the same with increase time. The galvanic current density estimated by use ZRA, where the Ni_Cr alloy is connected to the positive terminal of the ZRA and the $\mathrm{Cu}$ is connected to the negative terminal.

Figure (12) shows the variation of galvanic current of Ni- $\mathrm{Cr}$ alloy - $\mathrm{Cu}$ couple with time for different agitation velocities at $\mathrm{T}=40^{\circ} \mathrm{C}$. Under stagnant conditions, initially galvanic current is negative, then sharply increases to positive with time. The current is flowing from $\mathrm{Ni}_{-} \mathrm{Cr}$ alloy (anode) to $\mathrm{Cu}$ (Cathode) due to the minus sign in galvanic current. The corrosion of Ni_ Cr alloy decrease with time because the passivation layer formed on the surface as mentioned previously. Under flow conditions, is initially positive which 
means that it flows from the cupper to $\mathrm{Ni}-\mathrm{Cr}$ alloy. The current then decreases with time and after few minutes reaching to zero. The increase in the negative means that the direction of the current is reversed, i.e becomes from $\mathrm{Ni}-\mathrm{Cr}$ to $\mathrm{Cu}$. This behavior is thought due to the formation of passivation layer on the $\mathrm{Ni}-\mathrm{Cr}$ at first moments of coupling causing it to behave as cathode. After few minutes and by the action of agitation velocity this layer is removed leading to activate the anodic action of Ni-Cr alloy. It can be seen from Figure (12) that after the sharp increase in the negative direction, the current starts to shift to the positive direction, i.e. the absolute value is decreased. This can be ascribed to the decreased surface activity and formation of corrosion layer on the anode. In general, the higher the velocity is the higher the absolute value of the galvanic current. This behavior of the anode corrosion current agrees with [23,7].

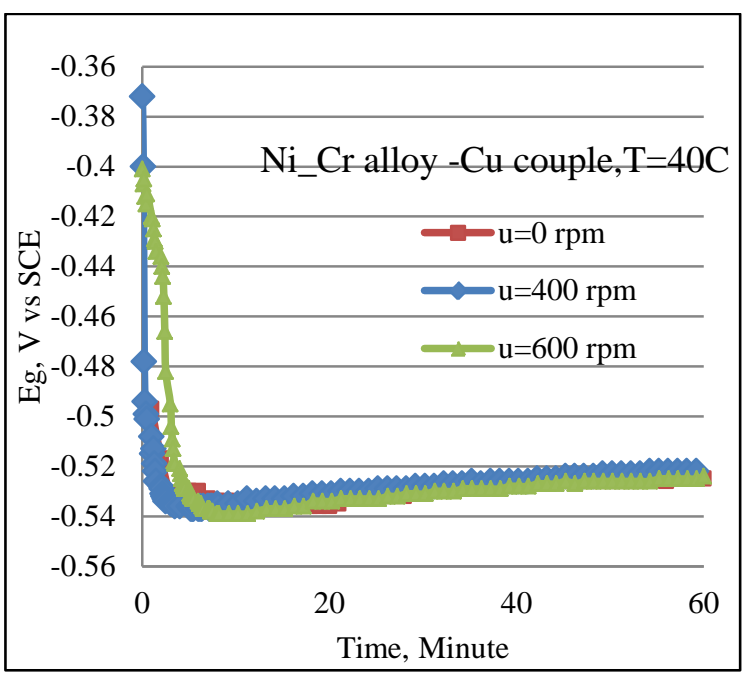

Figure 11: Effect of agitation velocity on the galvanic potential (Ni-Cr alloy-Cu couple).

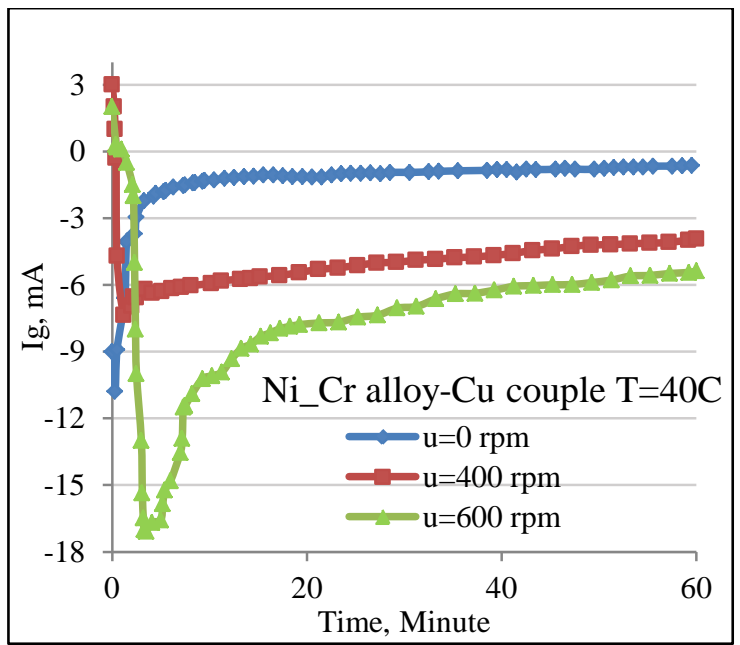

Figure 12: Effect of agitation velocity on the galvanic current (Ni-Cr alloy-Cu couple).
Table 3 shows the values of corrosion rate obtained from weight loss of $\mathrm{Ni}$ - $\mathrm{Cr}$ alloy and $\mathrm{Cu}$ in both free and coupling cases. The values of corrosion rate reveal that the corrosion rate of $\mathrm{Ni}$ $\mathrm{Cr}$ alloy is higher than for $\mathrm{Cu}$ suggesting that $\mathrm{Ni}$ $\mathrm{Cr}$ alloy is anodic and $\mathrm{Cu}$ is cathodic. That is supported by the trend of open circuit potential of the two metals (Figures 8 to 10). In addition, when coupling $\mathrm{Ni}$ - $\mathrm{Cr}$ alloy with $\mathrm{Cu}$, it is found that the corrosion rate of two metals decreases. This is due to dissolution occurring on to metals and which is high for the nickel-chrome alloy surface. Black smut of elemental nickel formed on copper after the experiments confirming the dissolution of both metals. This result is in agreement with the previous work [24.25]. David et al., 1955 [24] for titanium and aluminum specimens coupled in sulfuric acid both metals corroded uniformly. Multicolored interference films were sometimes formed on titanium surfaces when no weight losses of titanium specimens were observed. Sheela et al., 2005 [25] found that in aluminum-nickel couple both metals corrode in 5\% sodium chloride acidified with acetic acid with the corrosion of nickel being considerably lower. The galvanic potential that was positive at the start, progressively decreased with time. the OCP of nickel exhibited a gradual increase in dissolution of nickel.

Table 3: Corrosion rate of Nickel_Chrome alloy and Copper in free and coupling at different agitation velocities and $\mathrm{T}=40^{\circ} \mathrm{C}$.

\begin{tabular}{|c|c|c|c|c|}
\hline \multirow{2}{*}{$\begin{array}{c}\text { u, } \\
\text { rpm }\end{array}$} & $\begin{array}{c}\text { Ni-Cr } \\
\text { alloy } \\
\text { free }\end{array}$ & Cu free & $\begin{array}{c}\text { Ni_Cr alloy } \\
\text { (+ve) } \\
\text { after coupled } \\
\text { to Cu (-ve) }\end{array}$ & $\begin{array}{c}\text { Cu (-ve) } \\
\text { After } \\
\text { coupled } \\
\text { to Ni_Cr } \\
\text { alloy(+ve) }\end{array}$ \\
\hline 0 & 2220.4 & 11.7073 & 2110.2 & 0 \\
\hline 400 & 2727 & 20.4878 & 1917.8 & 5.5749 \\
\hline 600 & 2949 & 72 & 2157.0 & 0 \\
\hline
\end{tabular}

\section{Conclusions}

From the experimental results, the following conclusions are drawn:

1- The free corrosion rate of $\mathrm{Ni}-\mathrm{Cr}$ alloy increases clearly with temperature while copper exhibits corrosion resistance for the whole range of temperature investigated

2- The corrosion potential of both metals shows considerable a decrease with time particularly at first few minutes of the exposure to the solution. It shows clear shift to more positive with the increase in temperature and in agitation velocity.

3- In galvanic coupling $\mathrm{Ni}-\mathrm{Cr}$ alloy with $\mathrm{Cu}$, the alloy behaves as an anode showing a clear increase in the corrosion rate. 
4- When coupling $\mathrm{Ni}-\mathrm{Cr}$ alloy with $\mathrm{Cu}$, the corrosion rate of each metal is lower than the free corrosion case. This is due to a dissolution occurring onto metals which increases on the nickel-chrome surface. Black smut of elemental nickel forms on copper after the experiments indicating the dissolution of both metals.

5- The corrosion rate of Ni-Cr alloy shows clear increase with the rotational speed, while the corrosion rate of copper show slight increase.

6- Under stationary conditions, the galvanic corrosion sharply increases with time. Under flow conditions, the absolute galvanic current increases with time during reaching an asymptotic value.

7- In general, increasing the rotational velocity leads to an appreciable increase in the absolute galvanic current.

\section{Nomenclature}

\begin{tabular}{|l|l|c|}
\hline $\mathrm{A}$ & surface area of specimen & $\mathrm{mm}^{2}$ \\
\hline $\mathrm{CR}$ & corrosion rate & $\mathrm{gm} / \mathrm{m}^{2}$.day \\
\hline $\mathrm{E}_{\mathrm{g}}$ & galvanic potential & $\mathrm{V}$ \\
\hline $\mathrm{E}_{\text {corr }}$ & corrosion potential & $\mathrm{V}$ \\
\hline $\mathrm{Ig}$ & galvanic current & $\mathrm{A}$ \\
\hline $\mathrm{t}$ & immersion time & $\mathrm{h}$ \\
\hline $\mathrm{T}$ & temperature & ${ }^{\circ} \mathrm{C}$ \\
\hline $\mathrm{u}$ & agitation speed & $\mathrm{rpm}$ \\
\hline$\Delta \mathrm{W}$ & weight loss & $\mathrm{gm}$ \\
\hline
\end{tabular}

\section{References}

[1] Talbot, D. E. J., Talbot, J. D. R., 1998. Corrosion Science and Technology, CRC series in materials science \& technology, New York.

[2] Abdallah M. and El-Etre, A.Y., 2003, Corrosion Inhibition of Nickel in Sulfuric Acid Using Tween Surfactants, Portugaliae Electrochimical Acta 21, PP. 315-326.

[3] Powell, C., 2002. Copper-Nickel Boat Hulls: Performance and Corrosion, Copper development association Inc., 2002

[4] Refaey S. A. M., Abd El Malak A. M., Taha F. Abdel-Fatah H. T. M., 2008, Corrosion and Inhibition of $\mathrm{Cu}-\mathrm{Zn}$ Alloys in Acidic Medium by Using Isatin, Int. J. Electrochem. Sci., 3, PP. 167 - 176.

[5] Mahato, B. K., Cha, C. Y., and Shemlit, W., 1980, Corrosion Science, Vol. 20, PP. 421441.

[6] Slaiman, Q. J. M., Basim O. Hasan, Hussein A. Mahmood, 2008, Corrosion Inhibition of Carbon Steel Under Two-Phase Flow (WaterPetroleum) Simulated by Turbulently Agitated System, The Canadian Journal OF Chemical Engineering, 86 (2), 240-248.

[7] Hasan, B. O., Galvanic corrosion of aluminum-steel under two-phase flow dispersion conditions of $\mathrm{CO}_{2}$ gas in $\mathrm{CaCO}_{3}$ solution, 2015. Journal of Petroleum Science and Engineering, 133, 76-84.

[8] Slaiman, Q. J. M., B. O. Hasan, 2010, Study on Corrosion Rate of Carbon Steel Pipe under Turbulent Flow Conditions, The Canadian Journal of Chemical Engineering, 88, 11141120.

[9] Guenbour A., C. Escrivà-Cerdán , E. BlascoTamarit , D.M. García-García , J. GarcíaAntón , 2012, Passivation behavior of Alloy 31 (UNS N08031) in polluted phosphoric acid at different temperatures, Corrosion Science 56, PP. 114-122.

[10] Hasan, B. O., S. A. Sadek, 2014, The effect of temperature and hydrodynamics on carbon steel corrosion and its inhibition in Oxygenated Acid- Salt Solution”, Journal of Industrial and Engineering Chemistry, 20, 297-307.

[11] Cifuentes, L., 1987. Electrochemical kinetics helps quantify corrosion phenomena, J.AntiCorrosion Methods and Materials, 34(11), 4-9.

[12] Hasan, B. O., Abdul Kader, H. D., and Abdul-Jabbar, M. F., 2011, Experimental Study on Carbon Steel Corrosion and its Inhibition Using Sodium Benzoate Under Different Operating Conditions, Iraqi Journal of Chemical and Petroleum Engineering, Vol.12, No.3, PP.11-24.

[13] Foroulis, Z. A., 1979, The Influence of Velocity and Dissolved Oxygen on the Initial Corrosion Behavior of Iron in High Purity Water, Corrosion, vol. 35, pp. 340-344.

[14] Silverman, D.C., Rotating cylinder electrode for velocity sensitivity testing, Corrosion, vol. 40, No. 5, pp. 220-226, 1984.

[15] Slaiman, Q. J., Abu-Khader, M. M., Hasan, B. O., 2007. Prediction of heat transfer coefficient based on eddy diffusivity concept. Trans. IChemE, Part A, Chem. Eng. Res. Design 85 (A4), 455-464.

[16] Ross, T. K., Wood, G. C., and Mahmud, I., 1966, The Anodic behaviour of Iron-Carbon Alloys in Moving Acid Media, J. Electrochem. Soc., Vol. 113, PP. 334-345.

[17] Chin, R. J., and Nobe, K., 1977. Electrochemical aspects of Steel Corrosion in Sea Water, Corrosion J., vol.33, pp.364.

[18] Nesic, S., Solvi, G. T., and Enerhaug, J., 1995, Comparison of Rotating Cylinder and Pipe Flow Test for Flow-Sensitive Carbon Dioxide Corrosion, Corrosion, vol. 51, pp. 773-787.

[19] Magaino S., 1997, Corrosion rate of copper rotating-disk-electrode in simulated acid rain, Electrochimica Acta, Vol. 42, No. 3, pp. 377382.

[20] A1-Hossani H.I., T.M.H. Saber, R.A. Mohammed, A.M. Shams E1 Din , 1997, 
Galvanic corrosion of copper-base alloys in contact with molybdenum-containing stainless steels in Arabian Gulf water, Desalination 109, PP. 25-37.

[21] Montañés M. T., R. Sánchez-Tovar, J. García-Antón, V. Pérez-Herranz, 2009, The influence of Reynolds number on the galvanic corrosion of the copper/AISI 304 pair in aqueous $\mathrm{LiBr}$ solutions, Corrosion Science 51, PP. 2733-2742.

[22] Hasan, B. O., 2014. Galvanic corrosion of carbon steel-brass couple in chloride containing water and the effect of different parameters, Journal of Petroleum Science and Engineering, 124, 137-145, 2014.
[23] Guenbour A., Sanchez-Tavar R., Montanes M.T., Garcia-Antor J., 2011, Galvanic corrosion of the base AISI 316l/Micro-Plasma arc welded AISI 3161 in polluted phosphoric acid media at different temperatures, Int. J. Electrochem. Sci., 6, pp. 3656-3670.

[24] David S., Charles B. K., Doms V. S., 1955, Galvanic Corrosion Behavior of Titanium and Zirconium in Sulfuric Acid Solutions, Journal of the electrochemical society, vol. 102, No. 3, pp.102-109.

[25] Sheela G., Muralidharan V.S., and Pushpavanam M., 2005, Corrosion behavior of electrochemically joined aluminum and stainless steel, Indian Journal of Chemical Technology, Vol.12, pp.466-471.

\section{التاكل الكلفاني لسبيكة التيكل كروم و النحاس في محلول حامض الكبريتيك تحث تاثير الجربان
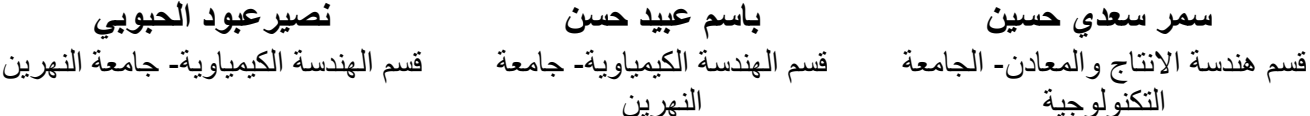

الخلاصة

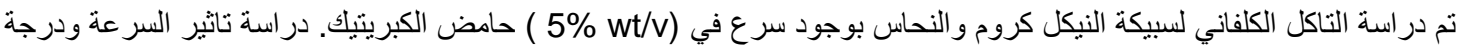

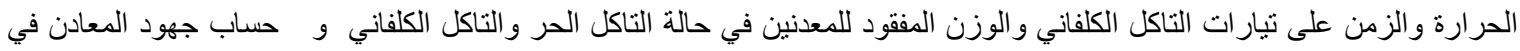

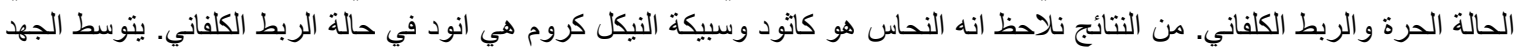

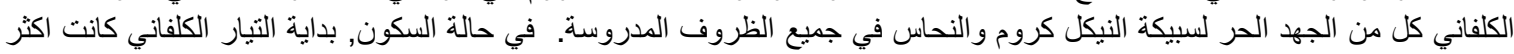

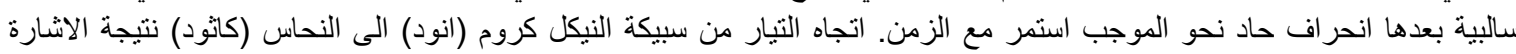

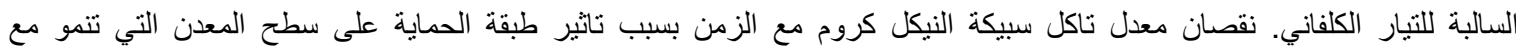

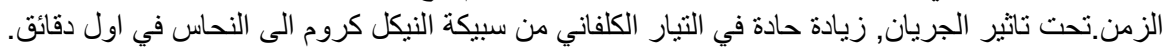

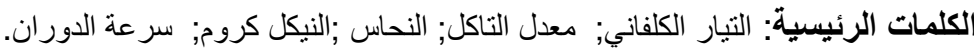

